\title{
Chemotherapy and Surgical Approach with Repeated Endovascular Embolizations: Safe Interdisciplinary Treatment for Kasabach-Merritt Syndrome in a Small Baby
}

\author{
Ghassan Nakib $^{a}$ Valeria Calcaterra ${ }^{\mathrm{b}, \mathrm{c}}$ Pietro Quaretti ${ }^{\mathrm{d}}$ \\ Lorenzo Paolo Moramarco $^{d}$ Giovanni Bonalumi ${ }^{\mathrm{e}}$ Marco Brunero $^{\mathrm{a}}$ \\ Gloria Pelizzo ${ }^{a}$ \\ Units of ${ }^{a}$ Pediatric Surgery and ${ }^{b}$ Pediatrics, Department of Mother and Child Health, \\ IRCCS Policlinico San Matteo Foundation and University of Pavia, 'Department of \\ Internal Medicine, University of Pavia, and ${ }^{\mathrm{d}}$ Unit of Interventional Radiology and \\ ${ }^{\mathrm{e}}$ Division of Vascular Surgery, IRCCS Policlinico San Matteo Foundation, Pavia, Italy
}

\section{Key Words}

Kasabach-Merritt syndrome $\cdot$ Endovascular embolization · Kaposiform hemangioendothelioma $\cdot$ Onyx-18

\begin{abstract}
Introduction: Kasabach-Merritt syndrome (KMS) is a life-threatening disease. We describe a combined medical and multistep, endovascular embolization that was successfully performed with surgery. Case Report: A 40-day-old female baby was referred because of an infiltrating pelvic mass. Blood tests showed severe anemia and thrombocytopenia with consumptive coagulopathy. The clinical aspect was pathognomonic for KMS. Administration of steroids and chemotherapy were started and coagulation parameters were normalized with tumor volume regression. Three months later, elective surgical treatment became possible, and dissection and ligature of the left internal iliac artery and sacral artery were performed. The main arterial supply of the mass was embolized with Spongostan ${ }^{\circledR}$. Two months later, a second hybrid approach was adopted for embolization of the main vascular supply of the tumor occupying the left thigh. Via a third contralateral hybrid femoral approach and under fluoroscopy, selective catheterization of the left profunda femoris artery was performed. The arterial feeder of the tumor, localized at the left gluteus, was seen on a CT scan 2 months
\end{abstract}

Prof. Gloria Pelizzo

Pediatric Surgery Unit

IRCCS Policlinico San Matteo Foundation

P. le Golgi n.2, IT-27100 Pavia (Italy)

E-Mail g.pelizzo@smatteo.pv.it 
Nakib et al.: Chemotherapy and Surgical Approach with Repeated Endovascular Embolizations: Safe Interdisciplinary Treatment for KMS in a Small Baby

later and was embolized with Onyx-18. Conclusion: Chemotherapy and a tailored hybrid approach comprising repeated endovascular embolizations seem to be a safe treatment in cases of unresectable and life-threatening tumors in small babies.

(C) 2014 S. Karger AG, Basel

\section{Introduction}

Kaposiform hemangioendothelioma (KHE) is a rare vascular tumor of infancy and childhood, with extremely aggressive behavior locally [1]. When associated with thrombocytopenia and consumptive coagulopathy, it is known as Kasabach-Merritt syndrome (KMS) [2].

Management of abdominopelvic KMS in infants is challenging due its infiltrating nature and risk of bleeding, and it presents a high mortality rate in newborns [3]. Steroids, chemotherapy and radiotherapy are not sufficient to induce total regression. Percutaneous embolization is feasible in children, but remains technically extremely difficult and dangerous in neonates and in small babies [4]. The treatment of choice is decided upon presentation of KMS in each individual patient, especially those in the first year of life.

We describe a combined medical and repeated endovascular embolization using a tailored surgical approach in a small baby affected with KMS. This treatment could represent an innovative multidisciplinary approach in infancy.

\section{Case Report}

A 40-day-old female baby was referred to our division for an abdominal mass that had been diagnosed in another institution. Upon physical examination, she presented a pelvic mass extending to the gluteus and left thigh. Left lower-extremity paralysis was noted. Blood tests showed severe anemia and thrombocytopenia. In the following hours, her hematologic status worsened due to consumptive coagulopathy and the increasing volume of the mass. The CT scan done on admission showed an infiltrating pelvic mass $(12 \times 8 \times 6 \mathrm{~cm})$ extending through the sciatic foramen to the left gluteus and thigh (fig. 1). The clinical aspect was pathognomonic of KMS.

Transfusion, steroids and chemotherapy (vincristine, prednisone, rapamycin and cyclophosphamide) were started immediately. Coagulation parameters were normalized and the patient stabilized. Three months later, regression of the tumor volume $(8 \times 4 \times 3 \mathrm{~cm})$ was observed and interventional treatment became possible. Surgical dissection and ligature of the left internal iliac artery and sacral artery were performed. The main arterial supply of the pelvic mass was then embolized using a gelatin sponge (Spongostan Haemostatic ${ }^{\circledR}$ ) under the fluoroscopy guidance of a portable C-arm tube in the operating room. At the control, complete regression of the pelvic mass and its vascularization were seen on the CT scan (fig. 2). A clear sensitive-motor improvement was observed.

Three months later, a second, similar, combined approach for the tumor occupying the left thigh was adopted. Surgical dissection of the left femoral artery and then partial embolization of the remaining tumor using a gelatin sponge (Spongostan Haemostatic) were successfully performed (fig. 3a). A third selective embolization of the arterial supply of the remaining tumor localized at the left gluteus region was planned for 2 months afterwards.

A hybrid approach to the contralateral femoral artery was achieved in the angiographic room using Philips Allura flat-panel angiography. The right femoral artery was dissected and a 4-french, valved introducer was placed in the right common femoral artery. The contrala- 
Nakib et al.: Chemotherapy and Surgical Approach with Repeated Endovascular Embolizations: Safe Interdisciplinary Treatment for KMS in a Small Baby

teral, left lower-limb angiography done with a 4-french, shaped Cobra catheter (Glidecath, Terumo, Tokyo, Japan) showed the main supply of the hypervascular tumor in the gluteus (fig. 3b). Using a 2.7-french Echelon (EV3) microcatheter, selective catheterization of the profunda femoris artery feeders supplying the tumor was performed. Angiographic devascularization was achieved under fluoroscopy after injection of $0.8 \mathrm{ml}$ of a nonadhesive, liquid glue, Onyx-18 (ethylene vinyl alcohol copolymer, Micro Therapeutics, Irvine, Calif., USA) (fig. 3c). Four months after treatment, the patient was stable.

\section{Discussion}

KHE is a rare vascular tumor that occurs nearly exclusively during childhood and the teenage years, with an equal sex distribution. Half of the lesions are present at birth, but $58 \%$ of the cases of KHE develop during infancy, 32\% in children between the ages of 1 and 10 years and $10 \%$ in children older than 11 years [4]. KHE affects the neck/head (in $40 \%$ of cases), trunk (in 30\%) or extremities (in 30\%). Numerous case reports have identified the lesion in noncutaneous locations, including the bone, mediastinum and peritoneum. The tumors are usually solitary; however, multifocal disease has been reported. Metastatic disease has not been reported $[4,5]$.

Mortality is high and ranges from 10 to $14 \%$, with a significantly higher rate for deep soft-tissue or visceral lesions occurring in infants younger than 6 months [6].

More than $50 \%$ of KHE cases are associated with a Kasabach-Merritt phenomenon, a condition characterized by thrombocytopenia and hypofibrinogemia with elevated markers of coagulation activation such as D-dimers or fibrin-degradation products; this association is known as KMS. KHE can be diagnosed by physical examination and medical history [6].

KMS is typically associated with more aggressive lesions and poorer outcomes [7]. Death most often results from expansive tumor growth and life-threatening hemorrhage $[8,9]$. The lesion is typically an ill-defined, red-to-purple indurate plaque; ecchymosis can be seen with or without teleangectasia and the lesions can have hypertricosis. The tumor may spontaneously decrease in size with time; however, complete regression is uncommon [6].

Characteristic imaging features may aid in the diagnosis of KHE. Magnetic resonance imaging is the modality of choice for the evaluation of tumor infiltration and expansion. Resonance angiography may better define arterial supply and venous drainage of the tumor. Computed tomography, ultrasound and radiographs are of limited usefulness in the evaluation of KHE [5]. On histological examination, the lesion is composed of infiltrating nodules with slit or crescent-like vessels that are poorly canalized and lined by spindled endothelium cells [1]. In our case, the patient had KMS based on the presentation and clinical findings. We performed CT angiography at the first admission due to the critical condition of the baby. Magnetic resonance imaging was done once her clinical condition had stabilized.

Due to the rarity of this lesion, there is no consensus on 'the best treatment'. Surgical excision is recommended when feasible [5]. Most patients with KHE present an infiltrating lesion, involving multiple tissue planes, nerves, blood vessels and other important structures; this presents a contraindication for surgery. Medical treatment is mandatory in the presence of KMS or when surgery is not possible; this includes chemotherapy (vincristine, actinomycin and cyclophosphamide), corticosteroids, interferon alpha, antiplatelet and antifibrinolytic agents and propanolol $[10,11]$. Radiation therapy has also been described as being successful for KHE [1,12]. Percutaneous embolization is performed in some types of 
Nakib et al.: Chemotherapy and Surgical Approach with Repeated Endovascular Embolizations: Safe Interdisciplinary Treatment for KMS in a Small Baby

vascular lesions, but is not recommended for the very young [4]. Embolization has been used to treat vascular tumors, but its indication and success in newborns with KHE and KMS are scarce [6]. The challenging percutaneous technique presents with unique aspects in neonates and small babies.

Experience in pediatric endovascular interventions is mandatory in order to avoid complications $[6,13,14]$. Very thin catheters are required to accomplish both angiography and embolization. Catheterization time must be very short to preserve the future patency and growth of the accessed and contralateral limb [3]. As for the contrast material, small amounts (up to $6 \mathrm{ml} / \mathrm{kg}$ body weight) may be used without adverse effects.

In our case, embolization was adopted as part of a more complicated surgical procedure, not only to decrease the flow of the vascular tumor but also to achieve a complete occlusion. Particulate embolic agents are well-suited to achieve this goal, but the use of liquid embolic agents has also been reported [3,13-15]. Both types were used in our case according to the specific angioarchitecture of the vascular tumors. Whereas reabsorbable gelatin sponge material in the hypogastric district may be injected with the aid of a portable C-arm tube, the embolization with nonadhesive, nonacrylic, liquid polymer agent Onyx-18 does require a high-level fluoroscopy control to avoid nontarget embolization. The microcatheter must be compatible with dimethyl sulfoxide, the solvent used for the dilution and delivery of Onyx18. The main advantages of Onyx-18 are its nonadhesive properties and radiopacity which allow more precise embolization. In addition, its greater biocompatibility causes less reactive inflammation than acrylic glues, thereby facilitating subsequent surgical resection if this has been planned $[14,15]$. In our case, the injection of $0.8 \mathrm{ml}$ of Onyx-18 was followed by an uneventful recovery. Surgical isolation of the artery in small babies and its embolization after securing the arterial branches reduce the risks of perforation and artery intimal dissection of the percutaneous technique. Postoperative pulse oximetry, continuous monitoring of the electrocardiogram and pressure and control of body temperature were conducted and these should be mandatory. The safety of the hybrid approach may extend the indications for imaging-guided embolization in small babies. Many possible different surgical approaches and materials for embolizing the pathologic targets should be considered.

\section{Conclusion}

When complete surgical removal is not possible or is contraindicated and medical treatment is not satisfactory, a combined therapy is mandatory. In our experience, chemotherapy and endovascular embolization by surgical approach seem most adequate in neonates and small infants in cases of infiltrating, unresectable, life-threatening tumors.

\section{References}

1 Fernández Y, Bernabeu-Wittel M, García-Morillo JS: Kaposiform hemangioendothelioma. Eur J Intern Med 2009;20:106-113.

2 Sarkar M, Mulliken JB, Kozakewich HP, Robertson RL, Burrows PE: Thrombocytopenic coagulopathy (Kasabach-Merritt phenomenon) is associated with kaposiform hemangioendothelioma and not with common infantile hemangioma. Plast Reconstr Surg 1997;100:1377-1386.

-3 Garcia-Monaco R, Giachetti A, Peralta O, Napoli N, Lobos P, Giosetti L, Mariani G: Kaposiform hemangioendothelioma with Kasabach-Merritt phenomenon: successful treatment with embolization and vincristine in two newborns. J Vasc Interv Radiol 2012;23:417-422.

4 Greene AK: Management of hemangiomas and other vascular tumors. Clin Plast Surg 2011;38:45-63. 


\section{Case Reports in Oncology}

\begin{tabular}{l|l}
\hline \multicolumn{2}{l}{ Case Rep Oncol 2014;7:23-28 } \\
\hline DOI: 10.1159/000357300 & $\begin{array}{l}\text { C 2014 S. Karger AG, Basel } \\
\text { www.karger.com/cro }\end{array}$ \\
\hline
\end{tabular}

Nakib et al.: Chemotherapy and Surgical Approach with Repeated Endovascular Embolizations: Safe Interdisciplinary Treatment for KMS in a Small Baby

5 Drolet BA, Trenor CC 3rd, Brandão LR, Chiu YE, Chun RH, Dasgupta R, Garzon MC, Hammill AM, Johnson CM, Tlougan B, Blei F, David M, Elluru R, Frieden IJ, Friedlander SF, Iacobas I, Jensen JN, King DM, Lee MT, Nelson S, Patel M, Pope E, Powell J, Seefeldt M, Siegel DH, Kelly M, Adams DM: Consensus-derived practice standards plan for complicated kaposiform hemangioendothelioma. J Pediatr 2013;163:285-291.

-6 O’Regan GM, Irvine AD, Yao N, O'Marcaigh A, Sheridan-Pereira M, Phelan E, McDermott MB, Twomey A, Russell J, Watson R: Mediastinal and neck kaposiform hemangioendothelioma: report of three cases. Pediatr Dermatol 2009;26:331-337.

7 Croteau SE, Liang MG, Kozakewich HP, Alomari AI, Fishman SJ, Mulliken JB, Trenor CC 3rd: Kaposiform hemangioendothelioma: atypical features and risks of Kasabach-Merritt phenomenon in 107 referrals. J Pediatr 2013;162:142-147.

-8 Enjolras O, Wassef M, Mazoyer E, Frieden IJ, Rieu PN, Drouet L, Taïeb A, Stalder JF, Escande JP: Infants with Kasabach-Merritt syndrome do not have 'true' hemangiomas. J Pediatr 1997;130:631-640.

-9 Mulliken JB, Anupindi S, Ezekowitz RA, Mihm MC Jr: Case records of the Massachusetts General Hospital: weekly clinicopathological exercises. Case 13-2004. A newborn girl with a large cutaneous lesion, thrombocytopenia, and anemia. N Engl J Med 2004;350:1764-1775.

10 Chiu YE, Drolet BA, Blei F, Carcao M, Fangusaro J, Kelly ME, Krol A, Lofgren S, Mancini AJ, Metry DW, Recht M, Silverman RA, Tom WL, Pope E: Variable response to propranolol treatment of kaposiform hemangioendothelioma, tufted angioma, and Kasabach-Merritt phenomenon. Pediatr Blood Cancer 2012;59:934-938.

11 Blatt J, McLean TW, Castellino SM, Burkhart CN: A review of contemporary options for medical management of hemangiomas, other vascular tumors, and vascular malformations. Pharmacol Ther 2013;139:327-333.

12 Malhotra Y, Yang CS, McNamara J, Antaya RJ: Congenital kaposiform hemangioendothelioma with KasabachMerritt phenomenon successfully treated with low-dose radiation therapy. Pediatr Dermatol 2013, E-pub ahead of print.

13 Cantasdemir M, Gulsen F, Solak S, Gulsen GY, Kantarci F, Numan F: The use of Onyx for embolization of peripheral vascular malformations in pediatric patients. Pediatr Surg Int 2012;28:477-487.

14 Soltanolkotabi M, Schoeneman SE, Alden TD, Hurley MC, Ansari SA, DiPatri AJ Jr, Tomita T, Shaibani A: Onyx embolization of intracranial arteriovenous malformations in pediatric patients. J Neurosurg Pediatr 2013;11:431-437.

15 Wohlgemuth WA, Uller W, Müller-Wille R: Liquid embolic agents - Onyx as problem solver. Radiologe 2013;53:223-229.
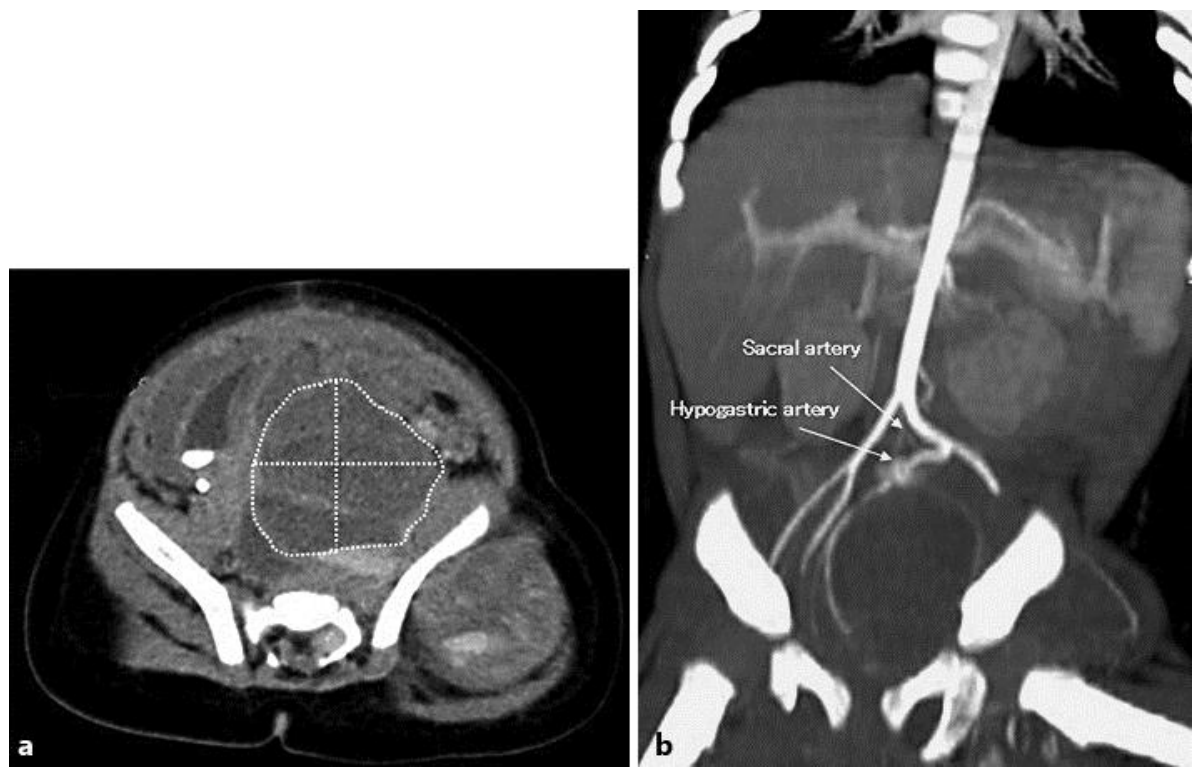

Fig. 1. Abdominopelvic hemangioendothelioma before chemotherapy. a CT scan: coronal view showing bladder displacement. b CT scan: main vascular mass supply. 


\section{Case Reports in Oncology}

\begin{tabular}{l|l}
\hline Case Rep Oncol 2014;7:23-28 & \multicolumn{2}{l}{} \\
\hline DOI: 10.1159/000357300 & $\begin{array}{l}\text { C 2014 S. Karger AG, Basel } \\
\text { www.karger.com/cro }\end{array}$ \\
\hline
\end{tabular}

Nakib et al.: Chemotherapy and Surgical Approach with Repeated Endovascular Embolizations: Safe Interdisciplinary Treatment for KMS in a Small Baby

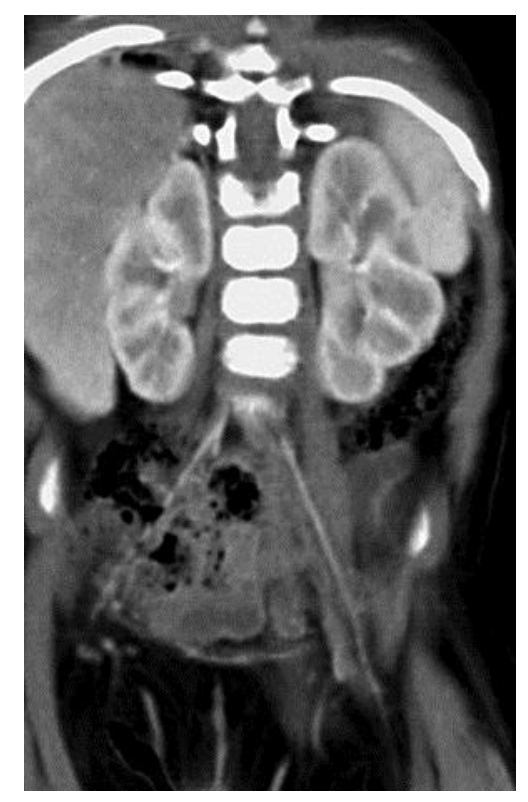

Fig. 2. Postembolization contrast CT study showing total devascularization and regression of the pelvic lesion.
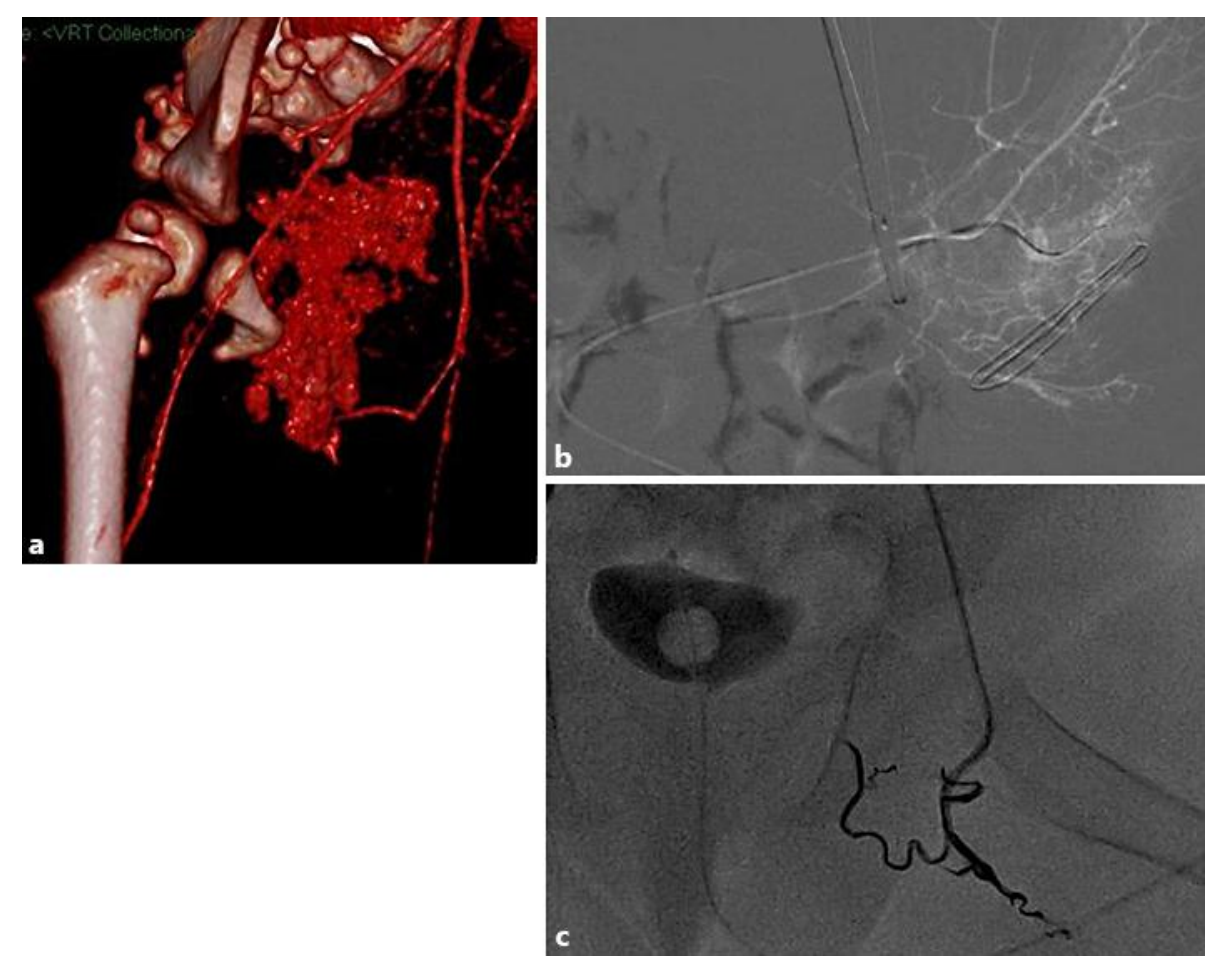

Fig. 3. Imaging findings. a Angiographic aspect: tumor occupying the left thigh before embolization. b Limb angiography: main feeder of remaining tumor of the gluteus. c Fluoroscopy: selective catheterization of the profunda femoris artery. Onyx-18 injection. 